\title{
Análise do Uso Turístico da Unidade de Conservação Refúgio de Vida Silvestre Metrópole da Amazônia (PA)
}

\section{Analysis of the Tourism Use of the Conservation Area Metropole da Amazônia Wildlife Refuge (PA, Brazil)}

\author{
Milene de Cássia Santos de Castro, Jonathan Rodrigues Nunes, \\ Silvia Helena Ribeiro Cruz, Fabrício Lemos de Siqueira Mendes
}

\begin{abstract}
RESUMO: O advento das Unidades de Conservação (UC), é visto pelo governo como uma das principais ações de preservação e conservação da biodiversidade. Dentre seus objetivos está a possibilitar que essas áreas possam evitar o uso desordenado de seu território. Dentre as classificações das UC, destaca-se neste artigo o Refúgio de Vida Silvestre (REVIS). Na Região Metropolitana de Belém - RMB (PA) destaca-se o REVIS Metrópole da Amazônia, criado no ano de 2010, em uma área de $63,67 \mathrm{~km}^{2}$, estabelecendo condições ambientais para existência ou reprodução de espécies de fauna e flora. Este estudo teve como objetivo indicar uma proposta de uso turístico para a unidade de conservação, a partir da análise de seu potencial turístico e o uso sustentável. Para isso, a metodologia partiu de pesquisas bibliográficas e documentais, bem como entrevistas com moradores e com representantes dos órgãos voltados a gestão da unidade e aplicação de questionários semiestruturados com os visitantes do REVIS. Os resultados obtidos por meio da atividade de campo culminaram na contextualização da localidade durante um período de 5 anos, do ano de 2013 a 2018. Os resultados obtidos apontam que são diversas as atividades turísticas sendo praticadas na localidade, no entanto, verifica-se que o REVIS ainda não possui uma infraestrutura adequada para visitação. Ressalta-se que a população residente no entorno da UC em muitos momentos ainda desconhece o motivo pelo qual a área virou uma unidade. Por isso estima-se a necessidade de reunir a população local os gestores, para discutirem os assuntos e rumos da UC.
\end{abstract}

PALAVRAS CHAVE: Turismo; Unidade de Conservação; Refúgio de Vida Silvestre Metrópole da Amazônia.

ABSTRACT: The advent of conservation area (UC in portuguese) its been see for the goverment it is one of the main actions of conservation of biodiversity. Among their objectives is to enable these areas to avoid the disorderly use of their territory. Among the classifications of the UC, stands out in this article, the Wildlife refuge (REVIS in portuguese). In the Metropolitan region of Belém - RMB (PA, Brazil), stands out the Metropole da Amazônia REVIS, created in 2010, in an area of $63.67 \mathrm{~km}^{2}$, establishing environmental conditions for the existence or reproduction of species of fauna and flora. This study aimed to indicate the proposal of the tourism use for this conservation area, based on the analysis of its touristic potential and sustainable use. For this, the methodology started with bibliographical and documentary research, and after this it was interviews with residents and representatives of the organs focused on the management of the area and application of semi-structured questionnaires with the visitors of the REVIS. The results obtained from the field activity culminated in the contextualization of the locality over a period of 5 years, from 2013 to 2018. The results obtained indicate that there are some tourist activities being practiced in the locality, however, it is verified that the REVIS does not yet have an adequate infrastructure for visitation. It is noteworthy that the population residing in the vicinity of the UC in many moments still does not know the reason why the area became a UC. Therefore, it is estimated the need to bring the local population to the managers, to discuss the subjects and directions of the UC.

KEYWORDS: Tourism; Conservation Unit; Metrópole da Amazônia Wildlife Refuge. 


\section{Introdução}

O turismo é considerado um fenômeno recente, que teve seu início no século XX com a grande expansão da revolução industrial, tendo como importante marco de crescimento a segunda metade do mesmo século, sendo considerado um grande vetor da economia mundial (SILVA, 2013). De acordo com Barretto (2000), Ignarra (1999) e Pires (1998) há diversos tipos de turistas e para cada um a uma segmentação, está sendo criada a partir de motivações e necessidades. Andrade (1976) destaca segmentos como Turismo cultural, religioso, de saúde, negócios, aventura e ecoturismo. Neste sentido destacasse a busca crescente por espaços naturais, que Boo (1992) classifica este segmento como a junção do turismo e dos preservacionistas.

Este segmento teve seu apogeu na década de sessenta, como termo para "explicar o intricado relacionamento entre turistas e o meio ambiente e culturas nos quais eles interagem" (HETZER, 1965 apud FENNELL, 2002, p. 42). Segundo Hetzer (2002) existem diversas características relacionadas ao segmento, porém, independentes fatores como impactos ambientais e culturais, benefícios econômicos e a satisfação do turista. Tais características revelam a importância quanto as questões ambientais, trazendo a discussão que o turismo deve repensar seu papel dentro da sociedade e tentar trazer um viés de conservadorismo.

No Brasil, o ecoturismo teve seu advento na década de 80, contudo o conceito oficial do Brasil apenas foi instituído em 1994 com o documento intitulado As Diretrizes para um Política Nacional de Ecoturismo, publicada pelo Instituto Brasileiro de Turismo (EMBRATUR), juntamente como Ministério do Turismo (MTUR) cujo conceito é:

\footnotetext{
Segmento da atividade turística que utiliza, de forma sustentável, o patrimônio natural e cultural, incentiva sua conservação e busca a formação de uma consciência ambientalista por meio da interpretação do ambiente, promovendo o bem-estar das populações (MTUR,2008).
}

Dentro de inúmeras literaturas se destaca a de Lindberg e Hawkins (1999) e Figueiredo (1999) que caracteriza o segmento como uma satisfação, pois o contato com a natureza torna-se o lugar propicio para realização da educação ambiental, desta forma minimizando os impactos sobre a comunidade autóctone.

\section{Breve histórico da criação de áreas protegidas e SNUC.}

A preservação do mundo natural, ou "mundo selvagem", teria surgido muito antes, no continente europeu como as mudanças de pensamento no que se refere ao mundo natural (DIEGUES, 1996). Até então, o pensamento principal era de desvalorização do mundo "selvagem", no que se relaciona à sua preservação. No entanto, influenciado pela evolução da História Natural, que deu importante contribuição no sentido de se firmar um olhar atencioso para com essas áreas naturais, a visão sobre elas teria começado a se alterar no sentido de sua valorização (THOMAS, 1983, apud DIEGUES, 1996).

Diegues (1996 p. 23) aponta que essa valorização do mundo selvagem, esteve enquadrada dentro da realidade de um contexto social em que "no começo da revolução industrial, a vida nas cidades, antes valorizada como sinal de civilização em oposição à rusticidade da vida no campo, passou a ser criticada, pois o ambiente fabril 
tornava o ar irrespirável'. Sendo assim, a vida campestre passou a ser sonhada pelas diversas classes sociais dentre elas a agrícola.

Diversos autores como Diegues (1996; 2000), Quintão (1993) afirmam que no início do século XIX, teria chegado aos Estados Unidos está ideia, até sua evolução criando deste modo o primeiro parque nacional Yellowstone. Entende-se que depois dos Estados Unidos, quem teria criado o primeiro parque nacional, diversos países começaram a adotar o mesmo sistema como Canadá (1885), Nova Zelândia e México (1894), África do Sul e Austrália (1898), Argentina (1903), Chile (1926) e o Brasil (1937).

No Brasil os parques nacionais, tinham como modelo a realidade norteamericana, não levando em consideração os aspectos da realidade nacional. Deste modo a população que residia em convertidas em áreas protegidas, principalmente as de populações tradicionais, foram banidas da possível moradia ou exploração sustentável dessas áreas e de seu processo de administração (AGUIAR, 2017). O advento dos Parques Nacionais no Brasil, foi o de Itatiaia, criado em 1937, no governo de Getúlio Vargas. Já em 1939 foram criados os parques de Nova Iguaçu, no estado do Paraná, e o da Serra dos Órgãos, no Rio Grande do Sul (BRITO; CÂMARA, 2001).

Após um período de 20 anos em 1959 foi repensado na criação de novos parques. Já na década de sessenta foram criadas diversas tipologias de Unidades de Conservação a exemplo dos Parques Nacionais (PARNA), Reservas Biológicas (RESEX), Estação Biológica, Área de Proteção Ambiental (APA), e Reservas Particulares do Patrimônio Natural (RPPN). Contudo em 1973 houve a criação da Secretaria Especial do Meio Ambiente (SEMA), com uma estrutura independente para questões ambientais, está criação se deu através das diretrizes da Conferência das Nações Unidas sobre o Meio Ambiente Humano, também conhecida como Conferência de Estocolmo, ocorrida em 1972.

Além da SEMA, outros conselhos, institutos e secretarias foram criados para gerir a gestão ambiental, no Brasil, foi criado o Conselho Nacional do Meio Ambiente (CONAMA) e o Sistema Nacional do Meio Ambiente (SISNAMA) através da lei nํ 6.938 de 1981. Já em 1996, a lei no 9.433 instituiu a Política Nacional de Recursos Hídricos e no mesmo período criou-se o Sistema Nacional de Gerenciamento de Recursos Hídricos e o Conselho Nacional de Recursos Hídricos, o Instituto Brasileiro do Meio Ambiente e dos Recursos Naturais Renováveis (IBAMA) em 1989 e o Sistema Nacional de Unidades de Conservação (SNUC), além de leis, portarias, resoluções e instruções normativas (LUSTOSA et al., 2003).

O SNUC foi criado através da Lei 9.985/2000, se caracterizando como um conjunto de unidades de conservação (UC) federais, estaduais e municipais. Composto por doze categorias, seu objetivo é específico e se diferencia quanto as formas de proteção e usos permitidos, maiores cuidados, pela sua fragilidade e particularidades, sendo distribuídas com de proteção integral, as áreas que podem ser utilizadas de forma sustentável e conservadas ao mesmo tempo e as de uso sustentável (BRASIL, 2000).

A visão estratégica que o SNUC oferece aos tomadores de decisão possibilita que as UC, além de conservar os ecossistemas e a biodiversidade, gerem renda, emprego, desenvolvimento e propiciem uma efetiva melhora na qualidade de vida das populações locais e do Brasil como um todo (VALLEJO, 2009). 


\section{Planejamento Ecoturístico em Unidades de Conservação}

A sustentabilidade é resultado da chamada "Era da Ecologia", no entanto esse legado intelectual teve suas primeiras manifestações desde o início do século XIX (HALL, 2001). Independentemente de a sociedade ter demonstrado disposição já no século anterior, em realizar atividades com cunho de conservar os recursos naturais, apenas no século XX essas atividades foram consolidadas (HALL, 2001). Essas questões sinalizadas pelo autor exerceram influência no planejamento ambiental e no seu direcionamento.

Por conseguinte, considerou-se ser pertinente apresentar a definição de planejamento, onde Hall (2001, p. 24) afirma que "o planejamento é um tipo de tomada de decisões e elaboração de políticas; ele lida, entretanto, com um conjunto de decisões interdependentes ou sistematicamente relacionadas e não com decisões individuais". Com a definição apresentada pelo autor, entende-se o planejamento como um processo de tomada de decisão com o enfoque coletivo. Hall (2001, p. 24) acrescenta que "pode ser difícil isolar muitas atividades desse processo, haja vista que o planejamento e outras atividades envolvem aspectos como barganhas e negociação, compromisso, coerção, valores, escolha e política".

Ainda para o autor acima, as exigências de realização de planejamento turístico e a intervenção pública (governo), em âmbito local, são prudentes contra os efeitos indesejados no crescimento do setor. Ao considerar o planejamento do turismo, é impossível a separação entre preservação e degradação, quando se discute acerca da relação entre comunidade local e ambiente natural. Para Albach et al. (2012 o desafio se caracteriza em encontrar meios de minimizar essa separação, a fim de preservar os recursos ambientais para as futuras gerações. A busca por ações de diminuição dos impactos ambientais está presente na maioria dos estudos Tuan (1980) e Machado (1996), afirmam que estas análises estão sendo recorrente, buscando melhorias para o convívio das comunidades autóctones e uso de áreas naturais.

O recorte utilizado por Albach et al. (2012), sinaliza o posicionamento de Ruschmann (2001, p. 27) de que "o turismo nos espaços naturais não é apenas modismo de uma época e a opinião pública tem se conscientizado, cada vez mais, da necessidade de proteger o meio ambiente". Albach et al. (2012), complementam que o aumento da procura por atividades vinculadas ao contato com a natureza, como por exemplo o ecoturismo, empreendimentos do setor turístico iniciaram ações direcionadas a diminuição destes impactos a fim de frisar a relação homem x natureza.

Ao definir o uso público de ambientes naturais, Barretto (1995) enfatiza que o termo público tem ligação com o conceito de estado, sendo um termo com possibilidades de interpretações diferenciadas. Ao relacionar as conotações do uso público e privado do espaço, a autora, evidencia a dicotomia dos usuários na utilização deste espaço. Ora, ao se apropriar do espaço público, tornando sua propriedade, ora a usufruir do espaço de modo inadequado.

Por uso turístico baseado nos estudos dos autores acima, entende-se a utilização de um espaço com relevância turística. Onde exista a possibilidade de realização de atividades de lazer. E, demanda de visitantes interessados em um contanto direto ou indireto com atrativos naturais e/ou artificiais. A partir dessa interação, a realidade ambiental é resultante dos processos subsequentes, onde a avaliação do uso do local turístico e o seu diagnóstico irá ser importante para a formulação de estratégias de fomento (LOMBARDO; CASELLA, 1999). 
Lombardo e Casella (1999) definem que o diagnóstico ambiental fornece as características de uma localidade, além de orientar as condições positivas e negativas e das possibilidades de evolução. Por outro lado, Rodrigues e Godoy (2013) ao direcionar o uso público diretamente em UC, evidencia que a utilização de áreas naturais para atividades de recreação e lazer são antigas. Essas ocorrem geralmente pela falta de espaços naturais públicos, devido a expansão das cidades.

\section{Área de estudo e processo de criação do REVIS}

O REVIS Metrópole da Amazônia foi criado a partir do decreto ํㅜ 2.211, de 30 de março de 2010, pela então Governo do Estado do Pará. Até o ano de 2014 a Secretaria de Meio Ambiente e Sustentabilidade (SEMAS) foi responsável pela administração da UC e presidência do Conselho Consultivo. A partir do ano de 2015 a gestão e atividades correlatas foram atribuídas ao Instituto de Desenvolvimento Florestal e da Biodiversidade do Estado do Pará (IDEFLOR-Bio) (IDEFLOR-Bio, 2015). A fiscalização da UC a partir da mudança de gestão continua sendo exercida pelo Batalhão de polícia ambiental (BPA) e por uma empresa particular de segurança. Sua localização encontra-se entre os municípios de Ananindeua, Marituba, Benevides e Santa Isabel do Pará. Com uma área de $63,67 \mathrm{~km}^{2}$ ocupa as coordenadas geográficas aproximadas de $01^{\circ} 23^{\prime} 30^{\prime \prime}$ a $01^{\circ} 29^{\prime} 30^{\prime \prime}$ de Latitude Sul e $48^{\circ} 10^{\prime} 00^{\prime \prime}$ à $48^{\circ} 22^{\prime} 00^{\prime \prime}$ de Longitude (W. Gr.), conforme Figura 1. Da capital paraense (Belém) a UC está localizada a $23 \mathrm{~km}$ de Belém, por via terrestre através da BR 316, e, por conseguinte, continua o trajeto por $4 \mathrm{~km}$ pela estrada da Pirelli. Além dos municípios fronteiras, a UC ao Sul dispõe de 18 km de margens em relação ao Rio Guamá (ALMEIDA, 2013).

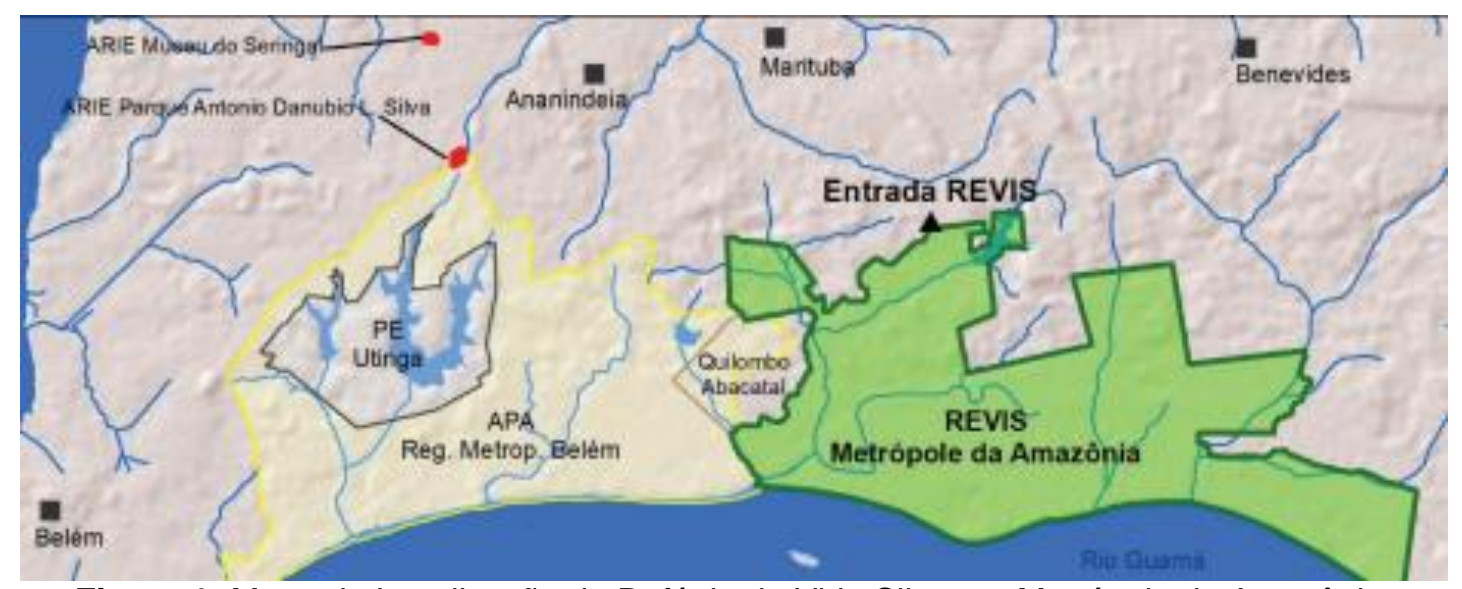

Figura 1: Mapa de Localização do Refúgio de Vida Silvestre Metrópole da Amazônia. Figure 1: Location map of the Refúgio de Vida Silvestre Metrópole da Amazônia.

Fonte: Instituto Avaliação (2017)

Source: Appraisal Institute (2017)

O REVIS Metrópole da Amazônia foi criado também com a finalidade de minimizar os impactos ambientais causados pelo crescimento populacional da Região Metropolitana de Belém. O nome escolhido para a UC ainda não se popularizou, sendo a área até o momento conhecida como "Fazenda Pirelli". Essa denominação é em decorrência devido a compra, em 1954, pela Empresa Pirelli AS. Neste período a área foi nomeada como Fazenda Guamá. Para a empresa de pneus Pirelli que iniciou o processo de cultivo de Seringueiras (Hevea brasiliensis), na década de 1950, teve por 
finalidade suprir a produção de matéria prima para os pneus produzidos em Merlo, Argentina. (ALMEIDA, 2013; CASTRO, 2013).

Ainda nos dias hoje, no local encontram-se edificações que pertenciam ao seringal da empresa Pirelli, como por exemplo as casas que pertenciam aos trabalhadores da extinta empresa (Figura 2). Há também uma estrutura de uma vila que servia de base para os trabalhadores e para os administradores da empresa, tendo funcionado na década de 1950 até meados da década de 1970 (PARÁ, 2009).

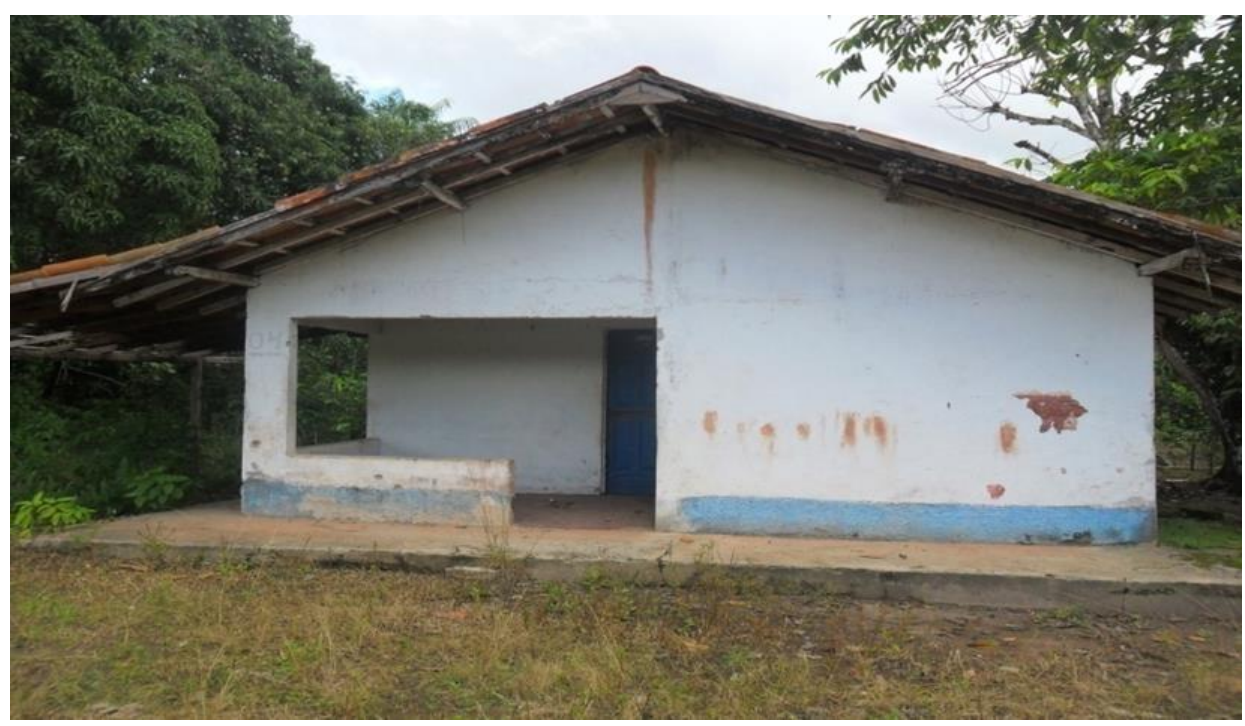

Figura 2: Tipo de Casa dos Trabalhadores da Empresa Pirelli.

Figure 2: Type of House of the employees of the Company Pirelli.

Fonte: CASTRO, 2013.

Source: CASTRO, 2013.

Essas edificações, encontradas no REVIS Metrópole da Amazônia, retratam o período conhecido como Belle époque. Este período trouxe mudanças na urbanização da região amazônica, sendo estas mudanças resultantes da riqueza obtida pelo comércio do Látex, matéria prima para a borracha. As cidades de Belém e Manaus concentraram o maior número de mudanças, essa riqueza influenciou novos costumes para a sociedade local (SARGES, 2002).

\section{Procedimentos Metodológicos}

A coleta de dados se deu em maio de 2013, através de entrevista com a gerente da unidade, que questionaram acerca das motivações de implantação da UC. Posteriormente, no mês de outubro de 2015, foi entrevistado a Bacharel em Turismo responsável pelo uso público do REVIS Metrópole da Amazônia. E, em seguida, com duas moradoras do REVIS, na Vila Três Marcos, com uma Bacharel em Turismo do Departamento de Turismo (DETUR) do município e com a aplicação de 45 formulários com moradores também do município de Marituba. Os locais de aplicação dos formulários foram: Mercado Municipal de Marituba, Praça Matriz da cidade e Bairro da Pirelli, localidade que se localiza o refúgio.

Por conseguinte, no ano de 2018 foi realizada também a Trilha do Quati, com a aplicação de 18 questionários, contudo, a pesquisa obteve 14 respostas. O questionário possuía 15 perguntas direcionadas para a avaliação das instalações do REVIS, eles foram repassados para os participantes da trilha, sendo todos estudantes 
de Turismo da Universidade Federal do Pará (UFPA). O período de envio das respostas dos questionários ocorreu entre os dias 7 de junho de 2018 ao dia 14 de junho de 2018.

\section{Análise dos resultados da pesquisa}

No ano de 2013 por meio de uma entrevista, via e-mail, com a Gestora do REVIS questionou-se qual a importância da criação do REVIS, qual o motivo da criação, como se deu esta criação, houve divulgação para os moradores dos municípios pertencentes à UC, por que a escolha da categoria de REVIS, houve apoio das prefeituras dos municípios pertencentes à unidade para a criação da mesma, são realizadas ações na área em âmbito ambiental e social, quais as principais mudanças desde a criação da UC, e qual a previsão de elaboração do plano de manejo.

Em relação as respostas das 5 primeiras perguntas, a gestora menciona que podem ser respondidas a partir das informações disponíveis nos documentos de criação do REVIS. No tocante ao apoio das prefeituras para a implantação do REVIS foi mencionado, o termo em parte, estima-se que as prefeituras foram avisadas do processo de criação, mas não participaram ativamente do mesmo. Em relação as ações ambientais e sociais a entrevistada mencionou que:

Estamos no processo de criação do conselho. Já realizamos 3 oficinas e no dia 12/04 será a oficina final, para escolha das instituições que farão parte do conselho.

Fazemos o monitoramento duas a três vezes por semana, ocasião que visitamos as comunidades, conversamos com os moradores, socializamos as atividades que realizamos, ouvimos reclamações, acionamos a fiscalização para combater ilícitos, etc.

Temos propostas de ações ao longo de todo o ano, já aprovadas no POA Planejamento Orçamentário Anual (POA) que envolvem várias ações sociais como cursos, oficinas e outras atividades para as comunidades residentes e do entorno (Informação verbal, 2013).

As principais ações no REVIS citadas foram: a manutenção dos ecossistemas, área livre de invasões, início de uma consciência ambiental por parte dos moradores da área e entorno. Por conseguinte, a criação do plano de manejo "Este ano iniciaremos o processo de contratação de empresa para organização. Também estamos conversando com o Museu Goeldi para que parte do Plano de Manejo seja elaborado por pesquisadores daquela instituição" (Informação verbal, 2013). O plano de manejo do REVIS ainda se encontra em construção.

No segundo momento de pesquisa, no ano de 2015, considerou-se as discussões sobre a análise de atividades turísticas em unidades de conservação, na perspectiva de uma observação e realização de pesquisa utilizando como base a estratégia fenomenológica, optou-se por coletar os dados em duas etapas: aplicação dos formulários e realização das entrevistas.

Neste período da pesquisa foram aplicados 45 formulários que objetivaram verificar o interesse da população do município de Marituba, representada por uma amostra não probabilística por conveniência, em realizar atividades turísticas de cunho 
ambiental no REVIS Metrópole da Amazônia. Nos formulários foram investigados: a idade, sexo, tempo de moradia, conhecimento sobre a existência da unidade de conservação, interesse em visitar e quais atividades poderiam ser realizadas na localidade.

Dentre os entrevistados 7 tinham idade entre 15 a 18 anos, 24 tinham idade entre 19 a 30 anos, 10 tinham idade entre 31 a 50 anos e 4 tinham idade entre 50 ou mais. Deste modo, houve uma participação expressiva de entrevistados na faixa etária entre 19 a 30 anos, acredita-se que este fato tenha ocorrido relacionado ao fato de os locais pesquisados serem em uma região de comércio. Também constatou-se ser mais fácil obter respostas do formulário na faixa etária de 31 a 50 anos. Infere-se que as faixas etárias mencionadas anteriormente, apresentaram indisponibilidade por estar trabalhando no momento da aplicação da pesquisa.

No tocante ao gênero, 27 entrevistados se identificaram como gênero feminino e 18 como gênero masculino. A partir das informações coletadas provenientes dos entrevistados, ocorreu uma maior participação feminina na realização da pesquisa, em relação à participação masculina. No que diz respeito aos locais de aplicação da pesquisa, no Mercado Municipal ocorreu a entrevista de 11 homens, na Praça de 5 Homens e apenas 2 no Bairro da Pirelli.

Em relação ao tempo de moradia, 5 entrevistados moram a menos de 1 ano, 7 moram entre 1 a 5 anos, 13 moram entre 6 a 10 anos e 20 moram entre 11 ou mais anos na localidade. A partir da aplicação dos formulários foi observado que a maioria dos entrevistados habitavam o município há menos de 10 anos. No entanto, inferiu-se ser tempo suficiente para conhecer o REVIS.

Por conseguinte, ao perguntar se os entrevistados conhecem ou já ouviram falar do REVIS Metrópole da Amazônia, obteve-se 16 negativas e 29 respostas afirmativas. Os entrevistados que responderam não conhecer o REVIS em sua maioria mencionaram morar no município de Marituba há menos de 5 anos, correspondendo a 12 entrevistados, entretanto 3 entrevistados mencionaram ser moradores há mais de 11 anos, também não conheciam e apenas 1 entrevistado morador há mais de 6 e menos 10 anos, respondeu não conhecer o REVIS. Em relação aos 29 entrevistados que responderam conhecer o REVIS, estes ainda não realizaram atividades no local.

Em relação ao interesse de conhecer o REVIS, 8 respostas foram negativas e 37 afirmativas. O interesse em conhecer o REVIS mostrou-se significativo, com 37 dos entrevistados declarando interesse em visitar a localidade. Em relação aos 8 dos entrevistados que optaram por não conhecer a localidade, afirmaram preferirem realizar outros tipos de atividades.

Para finalizar foi questionado aos 45 entrevistados, quais atividades eles teriam interesse em praticar na localidade, as respostas foram: observação da natureza foi mencionada 10 vezes, arvorismo 14 vezes, Cicloturismo 22 vezes, trilhas interpretativas 26 vezes, educação ambiental 27 vezes, caminhada 30 vezes e safári fotográfico 32 vezes. A atividade mais expressiva foi o Safári fotográfico, estimando-se que isso tenha ocorrido devido ao fato de ter sido realizado recentemente uma atividade semelhante no município.

As atividades propostas para a unidade de conservação foram retiradas do inventário para oferta turística, na categoria de atrativos naturais, elaborado pelo Ministério do Turismo. Posteriormente, serão apresentados os resultados da aplicação de entrevistas. 


\section{Resultado da Aplicação das Entrevistas}

Em relação aos critérios de escolha das entrevistas aplicadas com as duas moradoras do REVIS, foram baseados na disponibilidade das mesmas e realizadas na Vila Três Marcos, localizada na região pertencente ao município de Marituba. No tocante a entrevista realizada com a representante da gestão do REVIS, se deu com a responsável pelo uso público da unidade de conservação. E a respeito da última entrevista, buscou-se alguma atividade realizada no REVIS com a intenção de ratificar o interesse em práticas na unidade, com isso optou-se por entrevistar um representante do DETUR-Marituba.

A aplicação da pesquisa de campo buscou compreender o motivo de ainda não serem realizadas atividades turísticas no REVIS Metrópole da Amazônia, somente atividades de pesquisa. Objetivou compreender se o motivo desta ausência de atividades de cunho turístico seria o desconhecimento por parte da população do munícipio de Marituba ou uma opção da gestão da unidade e de seus moradores pela não realização de tais práticas.

No dia da realização das entrevistas, no dia 27 de outubro de 2015, apenas duas moradoras foram consultadas, tal número se justifica pela disponibilidade das moradoras em responder as perguntas desta pesquisa. A visita foi previamente agendada no IDEFLOR-Bio, e foi acompanhada por uma representante do instituto. As entrevistas com as moradoras ocorreram na Vila Três Marcos.

$\mathrm{Na}$ entrevista constavam 6 perguntas, a primeira pergunta indagava o tempo de moradia na localidade, as respostas foram dois anos e quatro anos. A segunda pergunta abordava as dificuldades de morar no REVIS, as respostas foram a falta de manutenção das casas e insegurança. A terceira questionou se a fiscalização estava sendo suficiente para a conservação do local, a resposta da primeira entrevista foi sim, e da segunda em partes por ainda ocorrer extração de palmito por pessoas externas ao REVIS.

A quarta pergunta questionou a participação em capacitações com o órgão gestor da unidade, essas capacitações estão relacionadas à manutenção dos recursos naturais do REVIS e a respeito da elaboração do plano de manejo, ambas responderam ter participado. A quinta pergunta, objetivou investigar o interesse na realização de atividades turísticas no REVIS, as moradoras responderam ter interesse, e comentaram sobre a realização de visitas organizadas pelo IDEFLOR-Bio e pelo antigo órgão gestor da unidade, a SEMA. A última pergunta solicitou a identificação dos locais mais bonitos do REVIS na perspectiva das moradoras, a vila, os igarapés, a mata e os animais foram as respostas.

\section{Entrevista com a Bacharel em Turismo responsável pelo uso público do REVIS}

A entrevista com a representante do IDEFLOR-Bio também ocorreu no dia 27 de outubro de 2015, foi composta de 11 perguntas. Sendo estas acerca da previsão de elaboração do plano de manejo e se as comunidades locais seriam retiradas, maiores dificuldades de gestão, relacionamento com os moradores, mudanças na fauna e flora da localidade, elaboração de plano de uso público e quais atividades seriam permitidas, uso público vigente do REVIS, atividades realizadas, controle de visitas, atividades turísticas que seriam permitidas, principais atrativos e fluxo de visitantes. 
Segundo a entrevistada, a criação e implantação do plano de manejo estava sendo cogitada para o ano de 2016. Com a contratação de uma empresa para a realização do plano. Os moradores não serão retirados da área, a entrevistada comentou que os moradores participaram dos projetos que estavam sendo elaborados para a localidade. No entanto, na Vila do Dique, localizada no munícipio de Marituba, não existiam mais moradores.

No tocante, às dificuldades de gestão, a entrevistada comenta que a fiscalização e a falta de manutenção do patrimônio foram os principais problemas citados. O relacionamento com os moradores se dava por meio de reuniões com os moradores, e com o conselho gestor do REVIS. Essas reuniões eram realizadas de três a quatro vezes por ano. A respeito das mudanças na fauna e na flora, mencionou não haver um levantamento sobre este tópico. No entanto, comentou que as espécies estavam se reproduzindo normalmente.

Comentou existir propostas de projetos para o uso público da UC, dentre estes projetos estava a de criação de um viveiro de Ararajuba (Guaruba guarouba), ave em risco de extinção, e encontradas na região amazônica; proposta de visitação de escolas ao REVIS; e quatro trilhas (Trilha do Seringal, Trilha do Quati, Trilha da Samambaia e Trilha da Estrada da Pirelli $(13 \mathrm{~km})$, exceto pela Trilha da estrada da Pirelli mencionou que as demais ainda não haviam sido medidas.

O uso público vigente caracteriza-se por visitações para a realização de pesquisas acadêmicas, visitações realizadas pelo IDEFLOR-Bio e raramente para a realização de passeios turísticos. Citou o evento Marituba in pixels, organizado pela Secretaria de Turismo de Marituba, que foi um concurso fotográfico tendo um dos seus cenários o REVIS Metrópole da Amazônia.

Dentre as atividades realizadas no REVIS, mencionou atividades de cunho e educacional, ambiental, fiscalização e pesquisa. No momento ao qual foi questionada sobre o controle destas visitações, relatou não existir uma catalogação de visitas, entretanto estas deveriam ser autorizadas pelo IDEFLOR-Bio.

Também foi comentado pela entrevistada, a proposta de reformar a antiga escola do local para servir de centro de visitação, com área para descanso e alimentação dos visitantes. Mencionou que a realização de atividades turísticas será permitida no REVIS, mas apenas atividades que estiverem de acordo com o plano de manejo a ser criado. Os principais atrativos na visão da entrevistada são fauna e flora do local. E finalizando, o fluxo de visitantes estava se dando majoritariamente por estudantes com o intuito de realizar pesquisas.

\section{Entrevista com uma representante do Departamento de Turismo de Marituba}

A entrevista ocorreu no dia 30 de novembro de 2015, onde aplicou-se o formulário de entrevista e objetivou a coleta de dados para analisar a motivação de escolha do REVIS Metrópole da Amazônia. Deste modo, a entrevistada relatou que o motivo de escolha do REVIS, foi a existência de apenas dois Refúgios de vida silvestre no Bioma Amazônia, também por ser a única unidade de conservação no município e ser pouco conhecida por seus moradores. Além do histórico de extração de látex ocorrida no local e da relevância histórica da localidade para o município. Abaixo uma imagem do safári fotográfico no REVIS (Figura 3). 


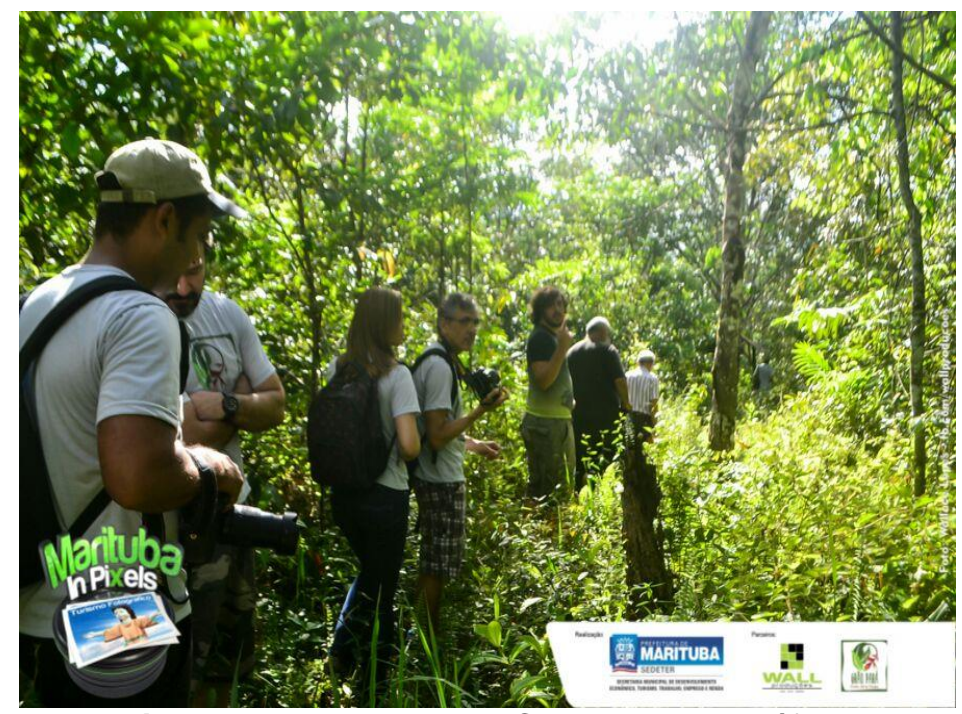

Figura 3: Realização Do Concurso Fotográfico.

Figure 3: Realization of the Photographic Competition.

Fonte: Departamento De Turismo De Marituba, 2015.

Source: Department of tourism To Marituba, 2015

Os participantes do evento realizaram duas visitas ao REVIS Metrópole da Amazônia, a primeira com 20 participantes e a segunda com 30. Sendo a última amplamente divulgada no município e na mídia social da secretaria. Em relação às parcerias somente ocorreu com o IDEFLOR-Bio e não com as demais secretarias de turismo dos municípios de que continham áreas pertencentes ao REVIS.

O terceiro e último momento de coleta de dados desta pesquisa, no ano de 2018, caracteriza-se por uma visita de campo para a realização de uma Trilha, organizada com a finalidade de identificar as possibilidades de práticas de lazer em UC, com o intuito de contribuir para o debate e elaboração de relatórios para a melhoria do trabalho da Empresa A. A mesma já realiza ações no REVIS e solicitou para a atividade uma taxa de manutenção de $R \$ 10,00$. Ela disponibiliza a prática de trilhas ecológicas, como a Trilha da Samambaia, Trilha do Quati e Ecobike.

A pesquisa realizada com os 14 estudantes de Turismo que responderam o questionário, demonstrou que $85,7 \%$ são do gênero feminino e $14,3 \%$ masculino. Com faixa etária de 19 a 29 anos. Dentre os entrevistados 85,7\% já haviam visitado o REVIS. Sendo que destes $87,5 \%$ a prática da visita de campo caracterizava-se como a segunda visita a UC. Consequentemente, em relação a localização do REVIS 57,1\% considerou de fácil acesso e contrapartida 42, 9\% considerou de difícil acesso.

No entanto, embora a maioria dos entrevistados considerem o local de fácil acesso, o mesmo não possui acessibilidade. $100 \%$ dos respondentes considerou que o REVIS não é adaptado para pessoas com mobilidade reduzida. Em relação a manutenção das instalações 42,9\% consideram péssima, 28,6\% consideram ruim, $21,4 \%$ regular e $7,1 \%$ bom. Não houve respondentes que consideraram as instalações excelentes. Em relação a sinalização externa $71,4 \%$ respondeu que não possui e 28 , $6 \%$ respondeu que possui. A partir das visitas para a realização da pesquisa, apenas uma placa na BR 316 sinalizando o REVIS. Em relação a sinalização interna 92,9\% evidenciam que não possui e $7,1 \%$ que sim o REVIS possuí. Em relação aos respondentes que já haviam visitado o REVIS, 100\% realizaram trilha. $50 \%$ dos entrevistados responderam que o REVIS possui instalações para a realização de visitações e 50\% não consideram. 
Em relação as práticas de lazer no REVIS, 42, 9\% classificam como bom, 28 , $6 \%$ como excelente e $28,6 \%$ como regular. Em relação a beleza do atrativo, $50 \%$ evidenciam como excelente, $42,9 \%$ como bom e 7, 1\% como regular. Em relação a segurança, $78,6 \%$ consideram regular, $14,3 \%$ bom e $7,1 \%$ excelente. Dos entrevistados $100 \%$ tem interesse em realizar outra atividade no REVIS. Para finalizar foi questionado o aprendizado no REVIS. Um dos entrevistados mencionou que:

Conhecer um pouco sobre a região onde moro, e as atividades econômicas que eram praticadas ali; Preservação do meio natural, bem como dos animais ali existentes; Contemplação da natureza e suas riquezas, tais como: plantas e igarapés; perceber a falta de integralização da população com os lugares naturais existentes dentro da Região Metropolitana de Belém (Informação verbal, 2015).

Também foi mencionado "a importância em conhecer a área e como podemos adaptar formas para trabalhar em uma área de preservação" (Pesquisa de campo, 2015). As demais respostas citadas foram: a História da Fábrica Pirelli, patrimônio histórico, preservação ambiental e importância do potencial turístico. Também foi citado "Em relação as espécies da fauna e flora e também em relação a história do ciclo da borracha" (Informação verbal, 2018).

\section{Considerações Finais}

O objetivo do presente estudo foi de analisar o uso turístico para a localidade, a fim de identificar a possibilidade de propor o estabelecimento de atividades que associassem os interesses da população local, gestores e visitantes. Para este fim o levantamento de dados relacionados à avaliação do uso turístico remeteu às diferenças estruturais, naturais, econômicas e sociais das diversas unidades de conservação do Brasil. Outro ponto relevante é a necessidade de implementação de infraestrutura turística para iniciar a prática de tais atividades e assim utilizar de modo menos impactante o vasto potencial tão propagado dos biomas brasileiros e a proporcionar a vivência entre homem-natureza.

A fim de verificar a possibilidade de fomento de atividades turísticas na Região Metropolitana de Belém, neste estudo se buscou apresentar como estava ocorrendo o processo de planejamento ambiental para atividades turísticas em unidades de conservação. Logo, neste estudo se objetivou também investigar qual a perspectiva do planejamento ecoturístico em relação aos elementos ambientais e sociais de UCs.

No entanto, infere-se que para a realização de atividades de cunho turístico em áreas naturais se faz necessário uma investigação do uso público e turístico das localidades. Em virtude dos dados mencionados é imprescindível que seja realizado levantamento prévio para a proposta de atividades turísticas. No caso do REVIS, os estudos técnicos acerca dos aspectos ambientais já foram realizados. Todavia, considerou-se de interesse para este estudo verificar por meio de entrevistas com uma amostra dos residentes a relevância desta atividade.

Em um primeiro momento, neste estudo observa-se a possibilidade de proposição de trilhas interpretativas no Refúgio, no entanto por falta do plano de manejo, e consequentemente, do plano de uso público, essa possibilidade foi refutada. 
Esta mudança no decorrer da realização da pesquisa de campo provou ser correta, por valorizar a análise prévia da atratividade dos recursos presentes na UC.

A análise foi fundamentada na explanação das características do refúgio, processo de criação de unidades de conservação, legislação federal de unidades de conservação, legislação na Amazônia, legislação no Pará, planejamento ecoturístico em unidades de conservação, uso público e uso turístico de unidades de conservação, interpretação ambiental, processos de avaliação de potencial turístico, procedimentos metodológicos e análise dos resultados. Acredita-se que este seja um modo coerente de apresentação de informações, que possibilitem 0 entendimento proposto pelo presente estudo.

Subsequentemente alguns dos temas apresentados no decorrer da pesquisa, como os procedimentos metodológicos e a análise dos dados, proporcionaram as respostas buscadas no início do estudo, tais temas elencaram a realidade da unidade em âmbito local por meio da realização da pesquisa de campo, e também do contato com os gestores e moradores da unidade. Desse processo emergiu o conhecimento ilustrado nos resultados.

Por meio do problema de pesquisa apresentado: qual seria o motivo de não ocorrer regularmente atividade turísticas no Refúgio de vida silvestre metrópole da Amazônia, deduz-se com base na pesquisa de campo que tais visitações não estavam acontecendo de modo regular por falta de atividades, estrutura de visitação e organização de roteiros destinados ao refúgio. Esta afirmação está fundamentada nas respostas dos entrevistados que em sua maioria afirmaram saber da existência da unidade e tinham interesse em visitá-la, assim como pela observação realizada com a visitação in loco.

No que diz respeito ao objetivo geral e aos objetivos específicos, os mesmos foram alcançados por meio de pesquisa bibliográfica e execução das entrevistas e formulários. Foi apresentado ainda o interesse dos moradores de Marituba em participar de atividades na unidade, a realização de um safári fotográfico na localidade, o interesse dos moradores locais em atividades turísticas no refúgio e os projetos direcionados a UC pelos gestores.

Indubitavelmente, constatou-se existir várias possibilidades de planejamento turístico para o Refúgio Metrópole da Amazônia, seja em âmbito de realização de atividades turísticas, ou seja, em âmbito acadêmico.

Ao concluir este estudo, verificou-se a necessidade de realização de mais visitas a unidade, esclarecendo-se que só foi possível visitar o local uma vez, esta visita durou cerca de cinco horas. Também deveria ter sido aplicado um formulário prévio, com o intuito de verificar a aplicabilidade das questões. Contudo acredita-se que os resultados deste estudo têm relevância, e espera-se que possam auxiliar pesquisas similares.

A aplicabilidade deste trabalho se relaciona às comunidades que vivem dentro do Refúgio de vida silvestre metrópole da Amazônia, como uma possibilidade de utilização do espaço. Também aos moradores do entorno da unidade como uma opção de lazer e aos gestores como uma possibilidade de gestão dos recursos e uso público. 


\section{Referências}

AGUIAR, H.J.P. Ecoturismo e tradição cultural quilombola: análise sobre as influências do turismo no Parque Estadual Caverna do Diabo nas comunidades de Ivaporunduva e Sapatu. São Paulo, Eldorado. 2017.

ALBACH, V.M; GÂNDARA, J.M.G; HACK NETO, E.; VIEIRA, V.B. O Pensamento de Lefebvre e os Usos e Consumos dos Espaços Turísticos. Revista Hospitalidade, São Paulo, v. xi, n. 1, 2012, p. 105-117.

ALMEIDA, M.P.R. Observação de aves no refúgio de vida silvestre metrópole da Amazônia: uma contribuição para a conservação ambiental da unidade e ao desenvolvimento turístico do estado do Pará. 2013. 134 f. Manaus: Dissertação Instituto Nacional de pesquisa da Amazônia (INPA). Mestrado Profissional em Gestão de Áreas Protegidas na Amazônia.

ANDRADE, J.V. Fundamentos e dimensões do turismo. B. Horizonte: Ática, 1976.

BARRETTO, M. Espaços públicos: usos e abusos. In: YÁZIGI. E; CARLOS, A.F.A; CRUZ, R.C.A. (Orgs.) Turismo: espaço, paisagem e cultura. Congresso internacional de geografia e planejamento do turismo "sol e território". Departamento de Geografia da Faculdade de Filosofia, Letras e Ciências Humanas da Universidade de São Paulo, 1995.

BARRETO, M. Turismo e legado cultural. 2000.

BOO, E. O boom do ecoturismo: planejamento para desenvolvimento e gerenciamento. Wildlands and Human Needs Program, 1992.

BRASIL. Lei 9985, de 18 de julho de 2000. Institui o Sistema Nacional de Unidades de Conservação da Natureza e dá outras providências. Brasília: Diário Oficial da União. 2000.

BRITO, F.A.; CÂMARA, J.B.D. Democratização e gestão ambiental: em busca do desenvolvimento sustentável. Editora Vozes, 1999.

CASTRO, M. C. S. Turismo em Unidades de Conservação: Uma Proposta para o Refúgio de Vida Silvestre Metrópole da Amazônia. 2013. 105 f. Trabalho de Conclusão de Curso. Belém: Universidade Federal do Pará (UFPA). Curso de Bacharelado em Turismo.

CRESWELL, J. W. Projeto de Pesquisa: métodos qualitativo, quantitativo e misto. 3. ed. Porto Alegre: Artmed, 2010.

CRITICAL ECOSYSTEM PARTNERSHIP FUND. Prioridades para Investimento do Fundo para Áreas Protegidas da Mata Atlântica. 2009. Disponível em: $<$ https://www.funbio.org.br/wp-content/uploads/2019/06/FMARJ-Fundo-da-Mata-Atl\% C3\%A2ntica-Um-mecanismo-inovador-de-financiamento-da-conserva\%C3\%A7\%C3 \%A3o-no-Rio-de-Janeiro.pdf>. Acesso em: 01/12/2015.

DENCKER, A. Métodos e técnicas de pesquisa em turismo. 2 ed. São Paulo: Futura, 1998.

DIEGUES, A.C.S. Populações tradicionais em unidades de conservação: o mito moderno da natureza intocada. In: Populações tradicionais em unidades de conservação: o mito moderno da natureza intocada. CEMAR/USP/NUPAUB, 1993.

DIEGUES, A.C.S. Etnoconservação: novos rumos para a conservação da natureza. Hucitec, 2000. 
FENNELL, D.A. Ecoturismo: Uma Introdução. São Paulo. Contexto, 2002.124p.

FIGUEIREDO, S.L. Turismo e cultura: um estudo das modificações culturais no município de Soure em decorrência da exploração do turismo ecológico. Turismo: impactos socioambientais. São Paulo: Hucitec, p. 207-222, 1999.

GIL. A.C. Como classificar as pesquisas? In: Como elaborar projetos de pesquisa. 4. ed. São Paulo: Atlas, 2002.

HALL, C.M. Planejamento turístico: políticas, processos e relacionamentos. São Paulo: Contexto, 2001.

IBGE CIDADES. Ananindeua, Marituba, Benevides e Santa Isabel do Pará. Disponível em: <http://www.cidades.ibge.gov.br/xtras/home.php>. Acesso em: 07/07/2015.

IGNARRA, L.R. Fundamentos do Turismo. rev. São Paulo: Pioneira Thomson Learning, 2003.

INSTITUTO DE DESENVOLVIMENTO FLORESTAL E DA BIODIVERSIDADE DO ESTADO DO PARÁ. Unidades de conservação. Disponível em: $<$ https://ideflorbio.pa.gov.br/unidades-de-conservacao/regiao-administrativa-debelem/refugio-de-vida-silvestre-metropole-da-amazonia/> Acesso em: 02/12/2015.

LINDBERG, K.; HAWKINS, D.E. Ecoturismo: um guia para planejamento e gestão. São Paulo: Editora SENAC São Paulo, 1995 e 1999.

LOMBARDO, M.A; CASELLA, L.L.D. Turismo ambiental: o caso de Bombinhas (SC). In: RODRIGUES, A.B. (Org.) Turismo e Ambiente Reflexões e Propostas. 2 ed. São Paulo: Hucitec, 1999.

LUSTOSA, M.C.J.; CÁNEPA, E.M.; YOUNG, C.E.F. Política Ambiental. In: MAY, P.H.; LUSTOSA, M.C.; VINHA, V. Economia do Meio Ambiente: teoria e prática. 2. ed. Rio de Janeiro: Campus Elsevier, 2003. 600p.

MACHADO, L.M.C.P. Paisagem valorizada - A Serra do Mar como espaço e lugar. In: DEL RIO, V.; OLIVEIRA, L. Percepção ambiental: A experiência brasileira. São Paulo: Nobel, 1996. p. 97-119.

MTUR, FGV. SEBRAE. Estudo de competitividade dos 65 destinos indutores do desenvolvimento turístico regional. Brasília, Distrito Federal, 2008.

PARÁ. Secretaria de Estado de Meio Ambiente e Sustentabilidade. Programa Estadual de Ordenamento Territorial. Consulta pública. Refúgio de vida silvestre. Belém: DIAP. Coordenadoria de Ecossistemas, 2009.

PIRES, B.C.C. Gestão em agências de ecoturismo e sua inserção no contexto da sustentabilidade. Turismo-Visão e Ação, v. 1, n. 2, p. 45, 1998.

QUINTÃO, A.T.B. Evolução do conceito de Parques Nacionais e sua relação com o processo de desenvolvimento. Brasil Florestal, v. 54, n. 2, p. 13-28, 1983.

RODRIGUES, C.G.O.; GODOY, L.R.C. Atuação pública e privada na gestão de Unidades de Conservação: aspectos socioeconômicos da prestação de serviços de apoio à visitação em parques nacionais. Revista Desenvolvimento e Meio Ambiente, v. 28, p. 75-88, 2013.

RUSCHMANN, D.V.M. O turismo rural e o desenvolvimento local sustentável: Turismo Rural e Desenvolvimento local sustentável. Campinas: Papirus, 2001. 
SARGES, M.N. Belém: Riquezas Produzindo a Belle Époque (1870-1912). 2.ed. Belém: Paka-Tatu, 2002.

SILVA, J.M. Política de turismo e representações da Amazônia: o turismo ecológico e cultural no estado do Amazonas. Novos Cadernos NAEA, v. 16, n. 1, 2013.

TUAN, Y. Topofilia: Um estudo da percepção e valores do meio ambiente. São Paulo: Difel, 1980. 288 p.

VALLEJO, L.R. Unidade de conservação: uma discussão teórica à luz dos conceitos de território e políticas públicas. Geographia, v. 4, n. 8, p. 57-78, 2009.

Milene de Cássia Santos de Castro: Universidade Federal do Pará, Belém, PA, Brasil. E-mail: castro.milene2010@gmail.com

Link para o currículo Lattes: http://lattes.cnpq.br/7458109805649246

Jonathan Rodrigues Nunes: Universidade Federal do Pará, Belém, PA, Brasil.

E-mail: jonathanrodrigues58@hotmail.com

Link para o currículo Lattes: http://lattes.cnpq.br/4108256284598873

Sílvia Helena Ribeiro Cruz, Universidade Federal do Pará, Belém, PA

E-mail: scruz@ufpa.br

Link para o currículo Lattes: http://lattes.cnpq.br/8432421463410679

Fabrício Lemos de Siqueira Mendes, Universidade Federal do Pará, Belém, PA, Brasil. E-mail: fabriciolsm@gmail.com

Link para o currículo Lattes: http://lattes.cnpq.br/7245720087255239

Data de submissão: 08 de março de 2019

Data de recebimento de correções: 01 de março de 2020

Data do aceite: 01 de março de 2020

Avaliado anonimamente 